\title{
The macroinvertebrate seedbank promotes community persistence in temporary rivers across climate zones
}

\author{
RACHEL STUBBINGTON* AND THIBAULT DATRY ${ }^{\dagger}$ \\ *School of Science and Technology, Nottingham Trent University, Nottingham, U.K. \\ ${ }^{\dagger}$ IRSTEA, UR-MALY, Lyon Cedex, France
}

\section{SUMMARY}

1. Aquatic macroinvertebrates inhabiting temporary rivers are typically described as having low resistance to riverbed drying. However, little research has examined the 'seedbank' within dry riverbed sediments, which comprises aquatic life stages that survive in dewatered sediments and from which active organisms may develop only after surface water returns.

2. We synthesised published and unpublished data from studies that had experimentally rehydrated sediments collected from dry riverbeds, to establish the importance of the seedbank in promoting macroinvertebrate community resistance. Studies from across climate zones were included, to examine seedbank importance in relation to environmental harshness and, in particular, sediment moisture. We also assessed the importance of the seedbank relative to alternative habitats promoting persistence of the flowing river (FR) assemblage. We predicted that the proportion of the FR assemblage present in rehydrated sediments (RS) would decrease with environmental harshness, due to conditions within the sediments becoming less conducive to the survival of biota.

3. A negative relationship between the proportion of FR taxa present in RS and harshness was observed, and this contributed to a reduction in the compositional similarity of FR and RS assemblages as harshness increased. Significant positive correlations were identified between sediment moisture content and macroinvertebrate community metrics (density and taxon richness) in some systems.

4. Habitats external to the dry reach, which contribute to community resilience, were invariably inhabited by a greater number of FR taxa than rehydrated sediments. However, rehydrated sediments included several FR taxa that were not found in any other habitats during the dry phase, including families of Coleoptera and Diptera.

5. Our results indicate the importance of the seedbank as a resistance mechanism for temporary river macroinvertebrates. With climate change scenarios predicting an increase in riverbed drying, maintaining habitats that facilitate the persistence of instream communities during dry phases is an increasing priority. We identified strong relationships between sediment moisture and taxon richness, and river management and rehabilitation activities should therefore aim to retain moisture in drying sediments, by manipulating parameters such as riparian shading.

Keywords: aestivation, egg bank, flow intermittence, refuge, seed bank

\section{Introduction}

Temporary rivers, which experience seasonal drying of riverbed sediments, are the dominant type of lotic ecosystem in Mediterranean and arid climates (Gasith \& Resh, 1999; Tooth \& Nansen, 2011) and are also common in temperate regions (Williams, 1996; Larned et al., 2010). In temporary systems, as well as in typically perennial rivers, the spatiotemporal extent of riverbed drying may increase during droughts (Williams, 2006; Sponseller et al., 2010; Bogan \& Lytle, 2011). Climate change scenarios predict an increase in drought

Correspondence: Rachel Stubbington, School of Science and Technology, Nottingham Trent University, Nottingham, Nottinghamshire NG11 8NS, U.K. E-mail: rachel.stubbington@ntu.ac.uk 
frequency and severity in many global regions (Solomon et al., 2007), with increasing water resource pressures exacerbating surface water deficits in anthropogenically influenced systems (Kundzewicz et al., 2008; Vörösmarty et al., 2010). The dry period duration in naturally temporary systems and the occurrence of drying in typically perennial rivers are therefore both expected to increase (Solomon et al., 2007; Döll \& Schmied, 2012), with consequences for the persistence of stream communities (Robson, Chester \& Austin, 2011).

Macroinvertebrate community responses to drying are considered to be characterised by low resistance (capacity to withstand drying) and high resilience (capacity to recover after flow resumes; Stanley et al., 1994; Fritz \& Dodds, 2004; Acuña et al., 2005). This means that recolonisation of a rewetted reach is achieved primarily by individuals originating from external sources, not by emergence of those withstanding drying in situ. However, this apparently low resistance conflicts with predictions that communities exposed to regular drying will have adaptive traits, including desiccation tolerance, to facilitate survival of dry phases (Lytle \& Poff, 2004; Diaz, Alonso \& Gutierrez, 2008; Robson et al., 2011).

Previous research considering macroinvertebrate survival within sediments extracted from dry channels has demonstrated that some taxa have active life stages that are resistant to drying, including dytiscid beetles (Fenoglio, Bo \& Bosi, 2006), gastropod molluscs (Miller,
Ponder \& Clark, 1999; Lysne \& Koetsier, 2006) and larval trichopterans (Wickson, Chester \& Robson, 2012). However, there is increasing recognition that these active individuals are only one part of an invertebrate 'seedbank' (sensu Tronstad, Tronstad \& Benke, 2005a; Datry, Corti \& Philippe, 2012), which comprises all aquatic life stages that remain viable in dry riverbed sediments. As such, the seedbank includes both active forms and dormant life stages that develop only after rewetting. The importance of seedbanks as a resistance mechanism has previously been recognised in temporary lentic waters including ponds (Kenk, 1949; Williams, 2005), wetlands (Dietz-Brantley et al., 2002; Brock et al., 2003) and floodplain habitats (Boulton \& Lloyd, 1992; Benigno \& Sommer, 2008), and in particular for meiofauna (Boulton \& Lloyd, 1992; Brock et al., 2003).

Recent sediment rehydration experiments have demonstrated that a substantial proportion of the macroinvertebrate community may also survive in the dry sediments of lotic ecosystems (see Table 1). Many of these published studies have provided system-specific indications of the taxa present in rehydrated sediments, while the wider importance of the seedbank as a mechanism allowing communities to persist in temporary rivers remains unclear (Zwick, 1996). A quantitative synthesis of existing data from across climate zones is required to improve understanding of the contribution the seedbank makes to community persistence in

Table 1 Characteristics of river systems included in the analysis of the macroinvertebrate seedbank

\begin{tabular}{|c|c|c|c|c|}
\hline Chester \& Robson (2011) & $\begin{array}{l}16 \text { streams, Victoria } \\
\text { mountain range, Australia }\end{array}$ & $\begin{array}{l}\text { Mediterranean } \\
\text { to semi-arid }\end{array}$ & $\begin{array}{l}\text { Varied between } \\
\text { streams }\end{array}$ & $\begin{array}{l}\text { Boulder and cobble sediments } \\
\text { over sandstone }\end{array}$ \\
\hline Larned et al., (2007) & $\begin{array}{l}\text { Mid-reaches, Selwyn River, } \\
\text { New Zealand }\end{array}$ & Temperate & $0.1-10$ & Glacio-fluvial deposits \\
\hline Paltridge et al. (1997) & $\begin{array}{l}\text { Lowland reach, Magela } \\
\text { Creek, Australia }\end{array}$ & $\begin{array}{l}\text { Tropical/ } \\
\text { monsoonal }\end{array}$ & 5 & $\begin{array}{l}\text { Sand dominated sediments over } \\
\text { sandstone }\end{array}$ \\
\hline Stanley et al., (1994) & $\begin{array}{l}\text { Mid-basin, Sycamore Creek, } \\
\text { Sonoran Desert, U.S.A. }\end{array}$ & Arid & $<9$ & $\begin{array}{l}\text { Coarse sand and pebble dominated } \\
\text { sediments }\end{array}$ \\
\hline $\begin{array}{l}\text { R. Stubbington, unpubl. } \\
\text { data b }\end{array}$ & $\begin{array}{l}\text { Upper reaches, River } \\
\text { Lathkill, England }\end{array}$ & Temperate & $2-3$ & $\begin{array}{l}\text { Mixed sediments over karst } \\
\text { limestone }\end{array}$ \\
\hline P. J. Wood, unpubl. data & $\begin{array}{l}\text { Chitterne Brook and } \\
\text { River Till, England }\end{array}$ & Temperate & 6 & $\begin{array}{l}\text { Gravel dominated sediment } \\
\text { over chalk }\end{array}$ \\
\hline
\end{tabular}

*Referred to as Lathkill headwaters (1) and (2), respectively, in figures.

(C) 2013 Blackwell Publishing Ltd, Freshwater Biology, 58, 1202-1220 
temporary rivers and to identify environmental drivers of seedbank composition. Previous experimental work and field observations have indicated that many taxa show partial but not complete desiccation tolerance (Robson et al., 2011; Wickson et al., 2012; Poznańska et al., 2013), which suggests that resistance is likely to be related to sediment moisture content.

We synthesised published and unpublished data to determine the importance of the seedbank as a resistance mechanism for macroinvertebrates in temporary rivers. Seedbank 'importance' was defined as the proportion of flowing river (FR) taxa present in the rehydrated sediment (RS) assemblage; this metric acknowledges the influence of the FR assemblage on that present in RS and also recognises that taxa need only survive at low abundance to contribute to community recovery upon rewetting. Studies from across climate zones were examined to determine how contrasting conditions, in particular environmental harshness (defined as conditions that limit community diversity and abundance; Fritz \& Dodds, 2005), influence the role of the seedbank. We hypothesised that the composition of the assemblage surviving in dry sediments would be related to harshness, and in particular to sediment moisture and therefore to the dry period duration, climatic variables and sediment characteristics. We predicted that the proportion of FR taxa in dry sediments would decrease in relation to harshness and that this would be observed as a reduction in taxonomic similarity between FR and RS assemblages as harshness increased. To establish the relative importance of the seedbank as one resistance mechanism within wider survival strategies, we examined the contribution of other habitats to the persistence of FR communities, including other instream areas promoting resistance (e.g. moist surface microhabitats) and instream and external habitats increasing resilience (e.g. the hyporheic zone and local perennial waters, respectively).

\section{Methods}

The data sets: criteria for inclusion and search parameters

Our synthesis examined macroinvertebrate persistence in lotic ecosystems following the loss of free water from the main channel; habitats lateral to the channel (e.g. floodplains) were not included. Flow intermittence occurs along a continuum, and we considered it arbitrary to define a cut-off point anywhere along this continuum; rivers with any degree of flow intermittence were therefore eligible for inclusion in our analysis, from ephemeral to near-permanent systems (sensu Williams, 2006).

For inclusion in our analysis of seedbank importance, a data set comprising two taxa lists was required: (i) taxa present in sediments extracted from a dry riverbed and experimentally rehydrated; (ii) taxa found within the same system during a period of surface flow either preceding and/or subsequent to the dry phase. 'Dry' sediments were considered as retaining a measured or undetermined amount of moisture but lacking free water. Dry sediments that were not rehydrated prior to examination were excluded, to avoid including deceased individuals in the recorded assemblage.

To warrant inclusion, the taxonomic resolution of a study needed to reach a level equivalent to other selected data sets, to facilitate comparison between systems. In practice, this meant Acarina, Oligochaeta and Tricladida were left at the group level stated; Bivalvia, Coleoptera, Diptera and Trichoptera were identified to family level; and Amphipoda, Cnidaria, Ephemeroptera, Gastropoda, Isopoda, Megaloptera, Odonata and Plecoptera were identified to genus. Meiofauna (Copepoda, Cladocera, Nematoda and Ostracoda) were excluded from our analyses as sampling and sample-processing methods were not suitable for their retention in many studies. Basic environmental information was required for each study system, including the climate zone and a qualitative description of sediment characteristics. Details such as sediment grain size distribution, moisture content and organic matter content were desirable but not essential, as such requirements would have excluded most data sets.

To identify relevant data sets, 89 searches incorporating combinations of 22 words or terms (aestivat*; desiccat*; dried sediment*; dry sediment*; egg bank*; eggbank*; emers*; ephemeral; intermittent; inundat*; invertebrate; macroinvertebrate; rehydrat*; re-hydrat*; rewet*; river; sediment*; seed bank*; seedbank*; stream; substrat*; temporary) were performed in the ISI Web of Knowledge database (Thomson Reuters, New York). Seven data sets fulfilling the criteria for inclusion were identified using this process: Boulton (1989), Stanley et al. (1994), Paltridge et al. (1997), Larned, Datry \& Robinson (2007), Stubbington et al. (2009), Chester \& Robson (2011) and Datry et al. (2012). Unpublished data underpinning the published work of Larned et al. (2007), Stubbington et al. (2009) and Datry et al. (2012) were used to supplement published results. Stanley et al. (1994) did not fully report the composition of the FR assemblage; in place of this, a satisfactory list was compiled from Stanley et al. (1994) and other studies 
conducted within the same system (Boulton et al., 1992; Velasco \& Millan, 1998; Sponseller et al., 2010). The FR assemblage relevant to Boulton (1989) was reported by Boulton \& Lake (1992). Paltridge et al. (1997) identified FR and RS samples using contrasting taxonomic approaches, with FR identification focussing on only three orders; this study was therefore excluded from certain analyses. In addition to the seven published studies, three unpublished data sets were acquired, two from R. Stubbington and one from P. J. Wood (Tables 1 \& 2), making a total of 10 data sets. Further information on the aims, study sites, methods and results of the three unpublished studies is provided in Appendix S1 of the Supporting Information.

Five of the 10 data sets fulfilling our basic criteria also investigated the effect of dry period duration on seedbank assemblages. Larned et al. (2007) and Datry et al. (2012) sampled multiple sites along a spatial gradient of increasing dry period duration. Stanley et al. (1994), Stubbington et al. (2009) and Stubbington (R. Stubbington, unpubl. data a) addressed the same question from a temporal perspective by sampling the same sites on repeated occasions during a prolonged dry phase. These five data sets were used to analyse the effect of dry period duration on seedbank composition, and where data were available (Larned et al., 2007; Datry et al., 2012; R. Stubbington, unpubl. data a), the effects of sediment moisture were also considered.

\section{Data analysis}

Determination of environmental harshness. To compare environmental conditions across studies, we ranked systems in order of relative harshness (i.e. conditions limiting survival of aquatic biota), where 1 reflected a relatively benign environment and 6 indicated the harshest conditions (Table 3). Ranks were based on sediment moisture content and were determined using quantitative measurements and qualitative descriptions, alongside factors influencing moisture content: dry period duration, climatic variables (temperature, precipitation inputs) and sediment characteristics (grain size distribution, organic matter content). All studies were conducted in reaches that typically dry annually (Table 1).

Conditions in Sycamore Creek (Stanley et al., 1994) were considered harshest (6) due to the effects of extreme high temperatures, virtual absence of precipitation and coarse sediment composition on sediment moisture retention (Table 1). The semi-arid Victoria Range rivers (Chester \& Robson, 2011) were also ranked as harsh (5), with drought conditions reducing average rainfall values (Table 3) and coarse sediments exacerbating water loss (Table 1). Of the temperate zone studies, Larned et al. (2007) noted very low mean \% sediment moisture; this study was therefore ranked as 4 (Table 3). Moisture content was not stated by Boulton (1989), but rainfall was similar to Larned et al. (2007), which in combination with higher maximum temperatures is likely to have limited sediment moisture retention; this system was therefore also ranked as 4 . Datry et al. (2012) recorded moderate moisture content, rainfall and temperatures, earning a rank of 3; in comparison, Stubbington (R. Stubbington, unpubl. data a) noted higher moisture, higher rainfall and lower temperatures, earning a rank of 2. Harshness assessment in two other temperate system studies (Stubbington et al., 2009; P. J. Wood, unpubl. data) was hampered by a lack of sediment moisture data; the climate and sediment moisture retention capacity of these systems were judged as comparable to Stubbington (R. Stubbington, unpubl. data a) and also assigned a rank of 2. Conditions reported by Stubbington (R. Stubbington, unpubl. data b) were most benign: the rainfall total was high, rain fell on 24/31 days in the dry month, and maximum temperatures (Table 3) were reached only briefly; this study was therefore allocated the lowest harshness rank (1; Table 3). Ranks were verified by researchers who had studied multiple systems (A. J. Boulton and P. J. Wood, pers. comm).

Environmental harshness and the importance of the seedbank. To test our prediction that the proportion of the FR assemblage surviving within dry sediments would decrease as harshness increased, we expressed the number of FR taxa present within the RS of a system as a proportion of FR taxon richness. Sampling effort and timing of FR sample collection varied (pre-drying, during the dry phase and/or post-drying; Table 2), but all studies strived to represent peak FR diversity, thus validating comparison between studies. To avoid overestimating richness, taxa lists were reduced to the coarsest resolution noted; for example, 'Limnephilidae (early instar)' and 'Limnephilus sp.' were considered one taxon. All terrestrial and semi-aquatic taxa were excluded. These measures resulted in some taxonomic totals differing from previously published values (e.g. Datry et al., 2012) and values stated in the Supporting Information (e.g. Table S2). Proportions were arc-sine square root transformed and then regressed against harshness ranks using linear and nonlinear models.

To test the prediction that RS and FR assemblages would become increasingly dissimilar as harshness 


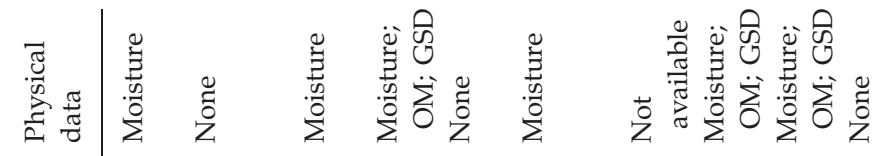

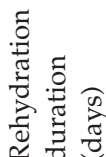

jo

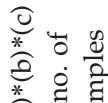

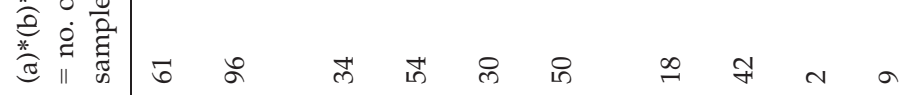

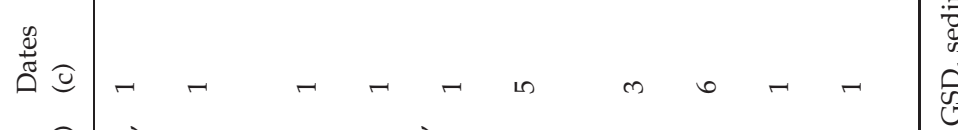

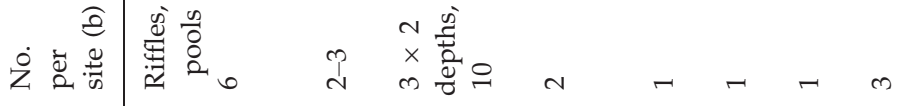

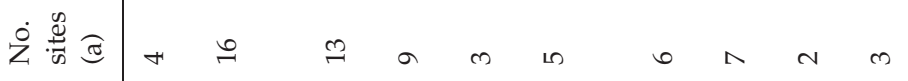

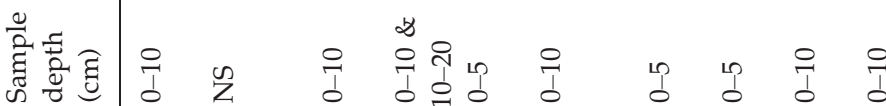

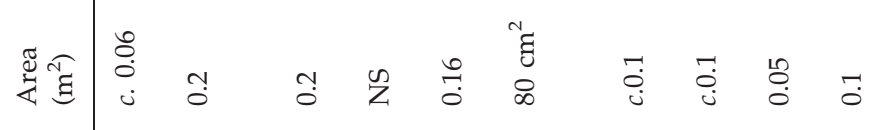

*

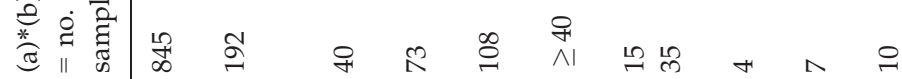

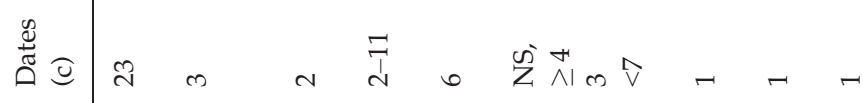

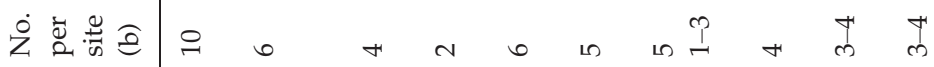

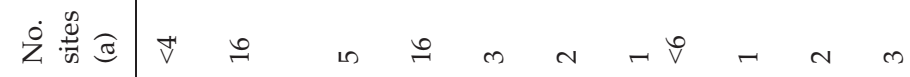

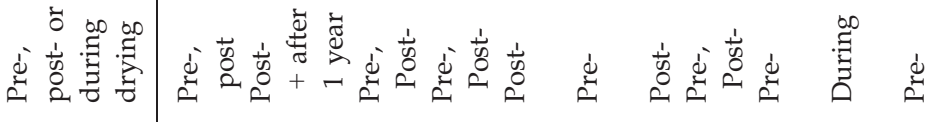

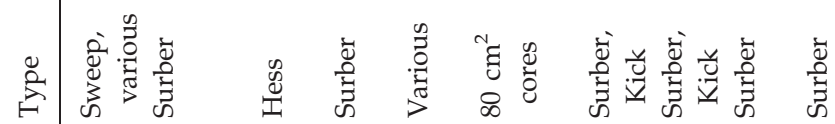

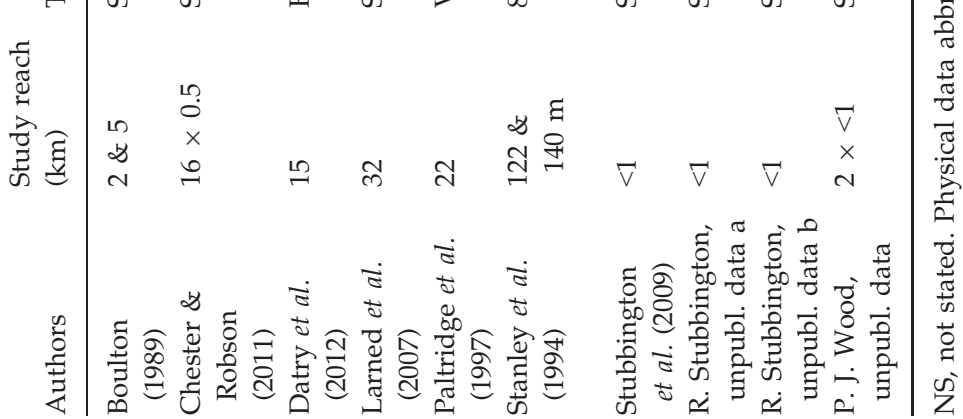


Table 3 Estimation of relative harshness of river systems from which rehydrated sediments were extracted

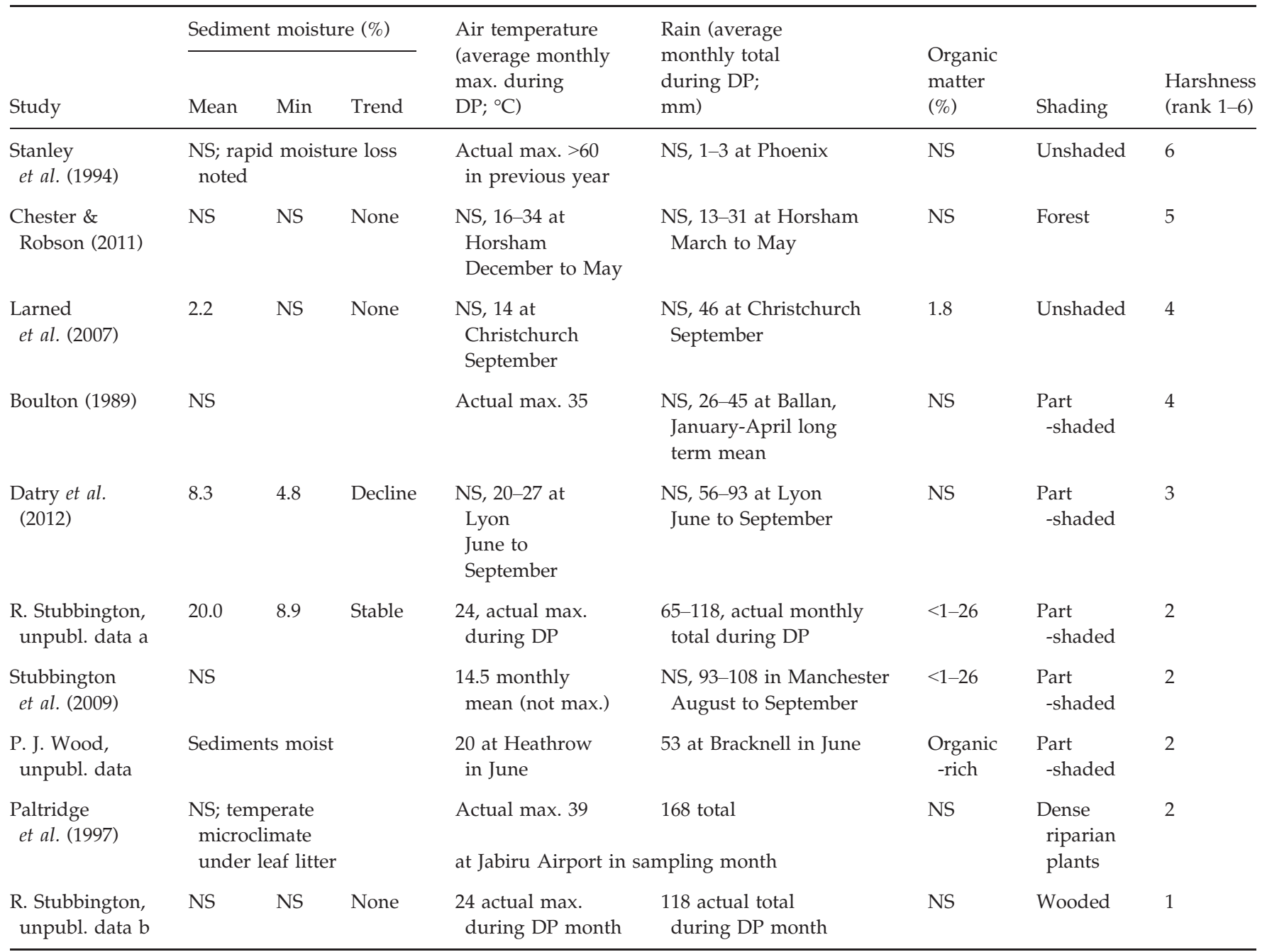

NS, not stated or not available; DP, dry period.

increased, non-metric multidimensional scaling (NMDS) was conducted, producing two-dimensional solutions that were ecologically interpretable (final stress $<0.2$; Clarke, 1993). For each system, the similarity between RS and FR assemblages was examined using Bray-Curtis distances based on taxonomic richness at the order level, to account for differences in taxonomic resolution between data sets. ANOSIM (analysis of similarity) was used to examine variability in FR and RS samples across harshness ranks using the ANOSIM test statistic $R$ (range -1 to 1 ); $\alpha=0.05$. Linear regression analyses were performed to examine relationships between RS-FR similarity values and harshness ranks.

Assemblage response to the dry period duration. To examine trajectories of change in seedbank assemblage composition with increasing dry period duration, NMDS was performed using a Bray-Curtis similarity matrix based on presence-absence data from the five suitable data sets. To explain patterns observed in the ordination, samples were allocated to one of four dry period durations $(0.1-7,8-30,31-63,64-287$ day) and taxon richness and macroinvertebrate density (converted to individuals $\mathrm{kg}^{-1}$ for all studies) calculated. The significance of temporal change in these community metrics was assessed using Kruskal-Wallis nonparametric one-way ANOVA tests, with Mann-Whitney $U$-tests to examine differences between pairs of durations. Abundance data were log-transformed prior to statistical analysis. Linear and nonlinear regression analyses were used to investigate relationships between community metrics and sediment moisture.

Seedbank importance relative to other persistence mechanisms. To determine the importance of the seedbank relative to other community persistence mechanisms, the 
occurrence of alternative sources of dry-phase survivors and recolonists was examined. Recolonist sources external to the dry reach comprised upstream and downstream perennial reaches, nearby lentic perennial waters and upwelling groundwater springs; instream recolonist sources included perennial pools and the hyporheic zone; habitats facilitating dry-phase resistance in situ comprised localised microhabitats such as leaf packs, bryophytes and filamentous algae. For all studies, the potential of each source as a persistence mechanism was estimated from its proximity to the dry reach and its spatial extent. Where data were available (eight studies), the number of taxa present in each alternative habitat was calculated and expressed as a proportion of the number of taxa in FR samples, to allow comparison with seedbank importance.

Significance testing and regression analyses were conducted in IBM SPSS Statistics 19 (IBM, New York, NY, U.S.A.), and NMDS and ANOSIM analyses were performed using PRIMER v6 (Clarke \& Gorley, 2006).

\section{Results}

\section{Assemblage composition}

An overall mean of $12.1 \pm 2.1$ taxa occurred in the study river systems. Total taxon richness was highest in the temperate Albarine (24 taxa; Datry et al., 2012) and Lerderderg and Werribee Rivers (22 taxa; Boulton, 1989) and lowest in the semi-arid Victoria Range rivers (three taxa; Chester \& Robson, 2011; Table 4). Chironomidae (Diptera) and Oligochaeta were the most common taxa, occurring in nine of ten river systems, while Ceratopogonidae (Diptera) was found in RS in eight studies. Some orders were represented by a diverse range of families, including Diptera (12 families), Trichoptera (11 families) and Coleoptera (eight families), while Odonata and Megaloptera were both represented by one species in one study (Table 4).

\section{Seedbank importance in relation to environmental harshness}

Considering all nine studies (but not Paltridge et al., 1997), a mean of $32.0 \pm 5.3 \%$ of FR taxa were present in RS. The proportion of the FR assemblage present in RS was highest in two temperate systems of low-to-moderate harshness (rank 1-3): the Albarine (54\%; Datry et al., 2012) and upper reaches of the Lathkill (52\%; R. Stubbington, unpubl. data b; Table 5). In contrast, Chester \& Robson (2011) noted only 5\% of the FR assemblage (a single taxon) in the RS of a harsh semi-arid system (rank 5). Other studies recorded $18-42 \%$ of FR taxa in RS, including systems with harshness ranks of 2 (e.g. Stubbington et al., 2009) to 6 (Stanley et al., 1994). Orders commonly present in FR samples but absent from RS included Ephemeroptera, Amphipoda and Hemiptera (Table 5). Regression analysis indicated a moderate linear negative relationship between environmental harshness and the proportion of FR taxa in RS $\left(R^{2}=0.339\right.$, $P=0.100$ ), which became significant when an outlying system (Sycamore Creek, U.S.A.; Stanley et al., 1994) was excluded $\left(R^{2}=0.647, P=0.016\right.$; Fig. 1$)$.

The NMDS ordination distinguished between FR and RS samples (ANOSIM $R=0.125, P=0.034$ ), with samples from individual systems plotting in variable proximity (Fig. 2). Sample pairs from harsher systems (ranks 4-6; Table 3) tended to be more distinct than pairs from more benign environments (ranks 1-3), with similarity between FR and RS assemblages being lowest in the Victoria Range (37.0; Chester \& Robson, 2011; rank 5) and highest in the Lathkill upper reaches (78.2; R. Stubbington, unpubl. data $b$; rank 1). Regression analysis indicated a linear decline in compositional similarity between FR and RS assemblages as harshness increased $\left(R^{2}=0.774, P=0.002\right.$; Fig. 3).

\section{Assemblage response to the dry period duration}

Non-metric multidimensional scaling indicated that sitespecific features were a greater influence on assemblage composition than dry period duration, with individual systems plotting as distinct clusters with minimal overlap (Fig. 4); in particular, samples from arid Sycamore Creek formed a distinct cluster separate from temperate systems. Trajectories of temporal change varied between systems (Fig. 4). In Sycamore Creek (Stanley et al., 1994), assemblage composition remained relatively stable over time and was not clearly related to dry period duration (Fig. 4). Assemblage stability was also observed in the Selwyn (Larned et al., 2007), with 1-d samples being more variable in composition than other samples. In contrast, in both the Albarine (Datry et al., 2012) and Lathkill headwaters (R. Stubbington, unpubl. data a), assemblage composition changed in relation to the dry period duration (Fig. 4).

Considering all five systems, taxon richness decreased steadily and became less variable as the dry period duration increased, from $9.4 \pm 1.3$ taxa for sediments exposed to $0.1-7$ day dry periods, to $4.7 \pm 0.3$ taxa where the dry period exceeded 64 days (Kruskal-Wallis, $P=0.001$; Fig. 5a). The reduction in density was

(C) 2013 Blackwell Publishing Ltd, Freshwater Biology, 58, 1202-1220 


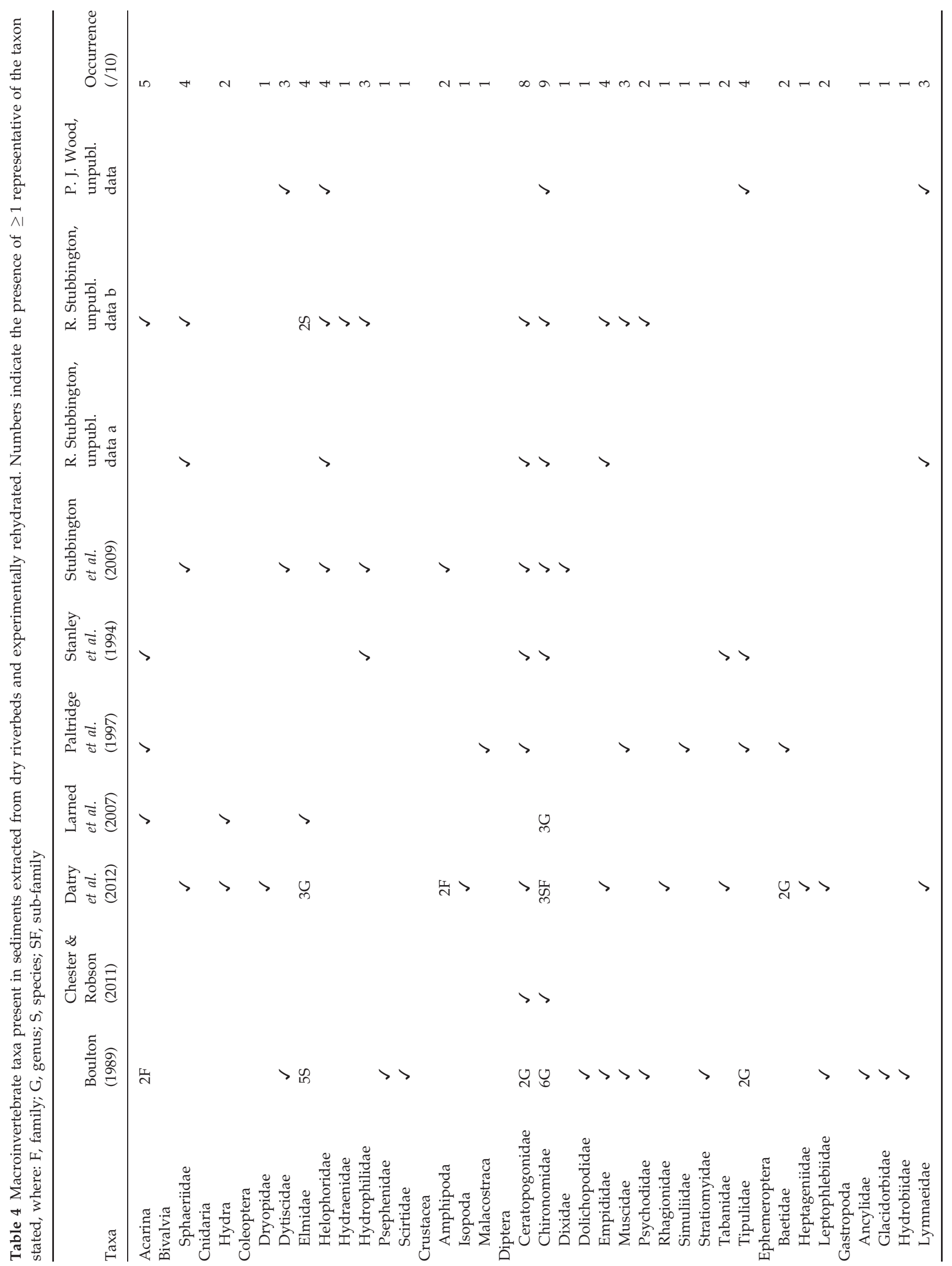

C 2013 Blackwell Publishing Ltd, Freshwater Biology, 58, 1202-1220 


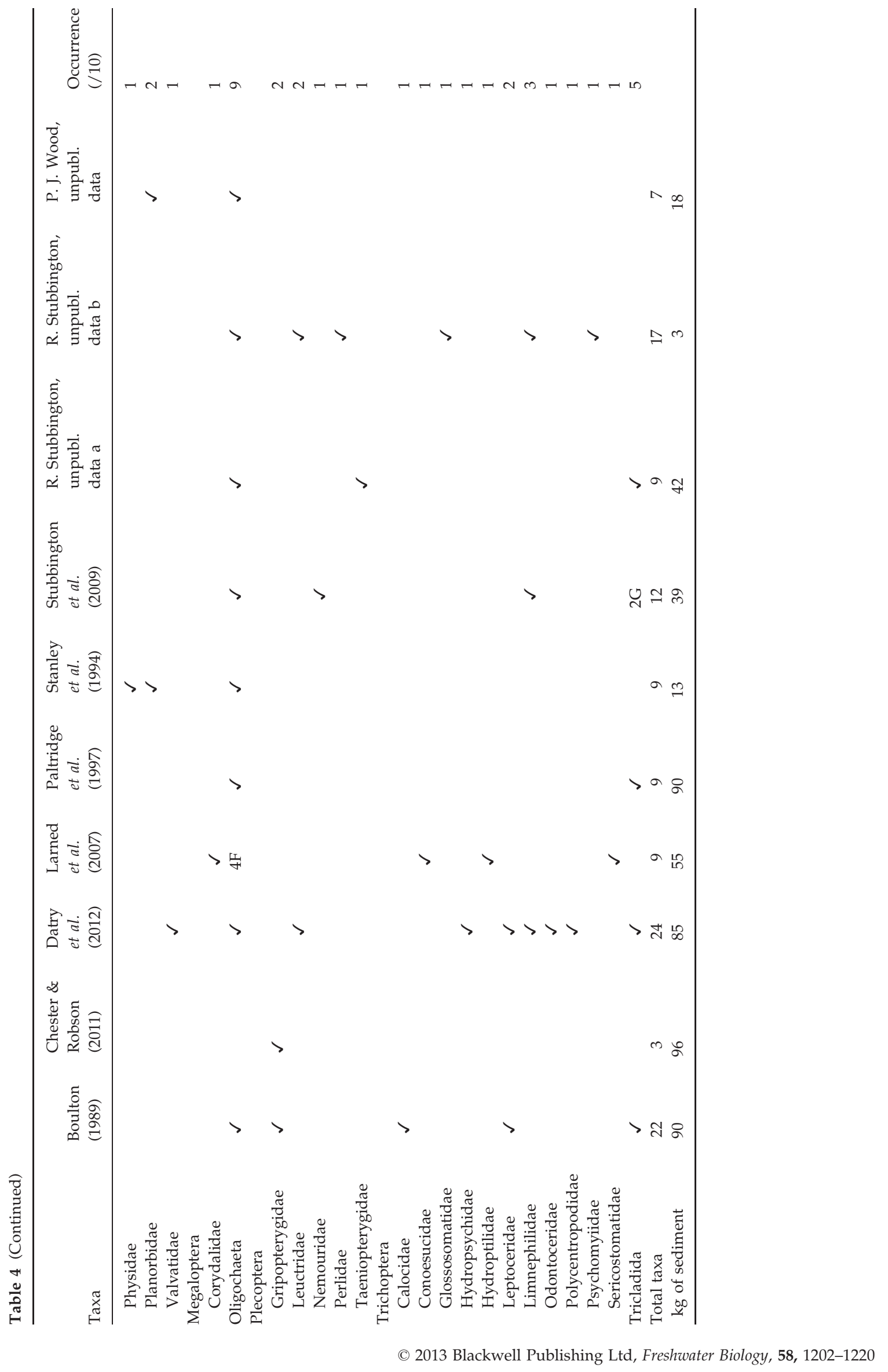




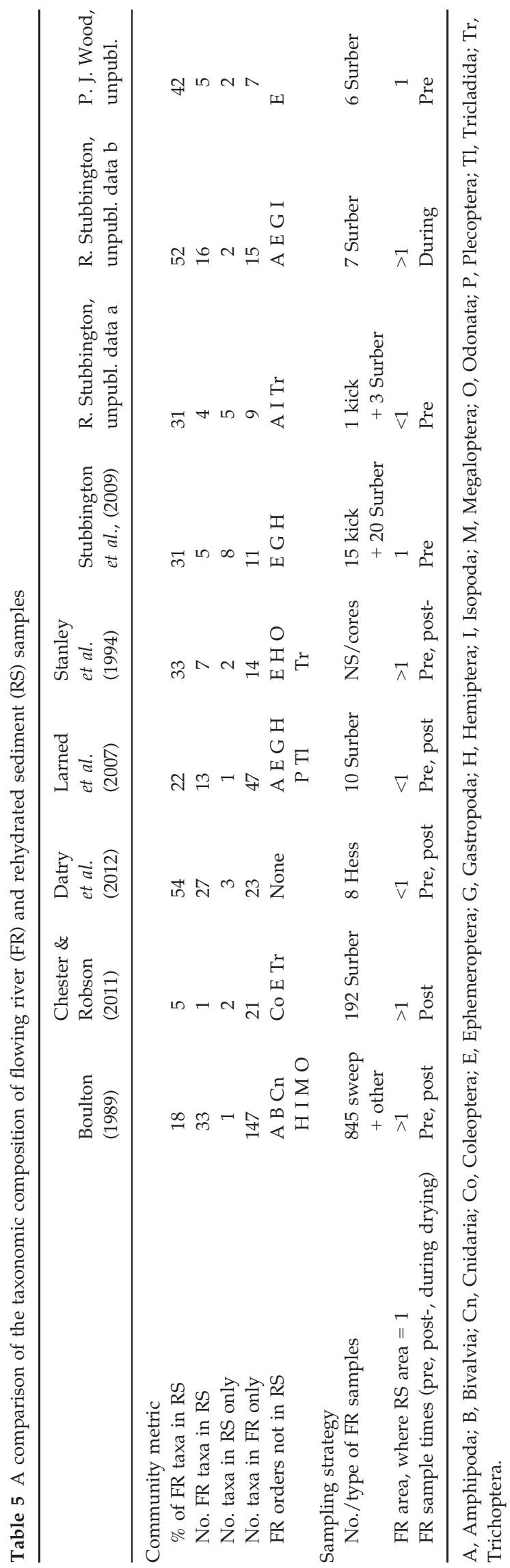




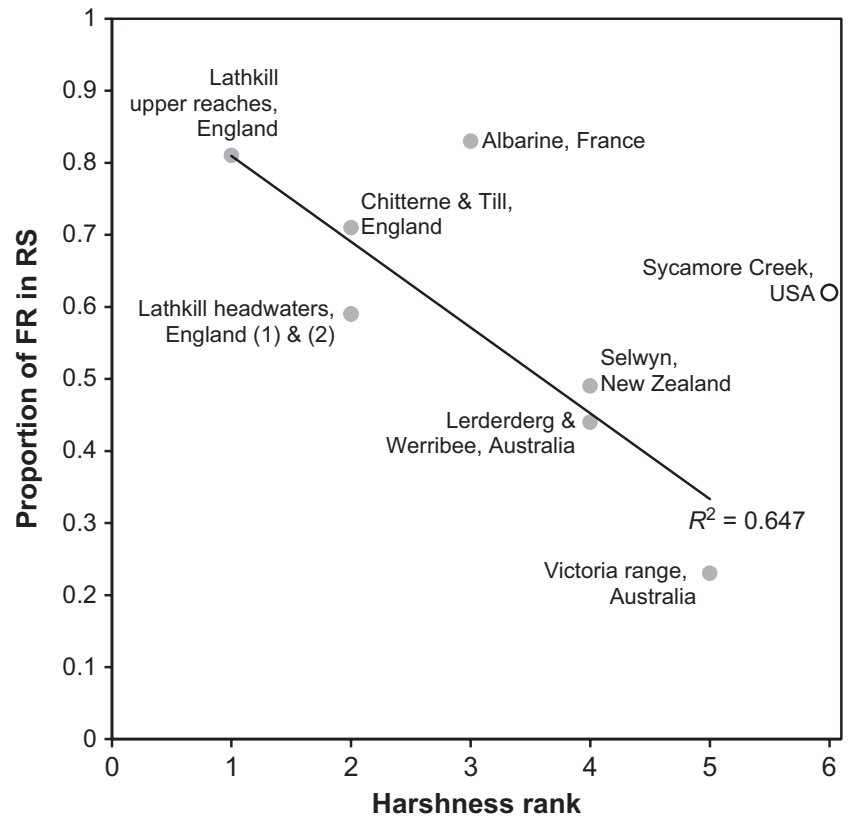

Fig. 1 Relationship between the proportion of flowing river (FR) taxa in rehydrated sediments (RS) and environmental harshness (see text for determination; $1=$ least harsh; $6=$ most harsh). Arcsine square root transformed data. See Table 1 for site details.

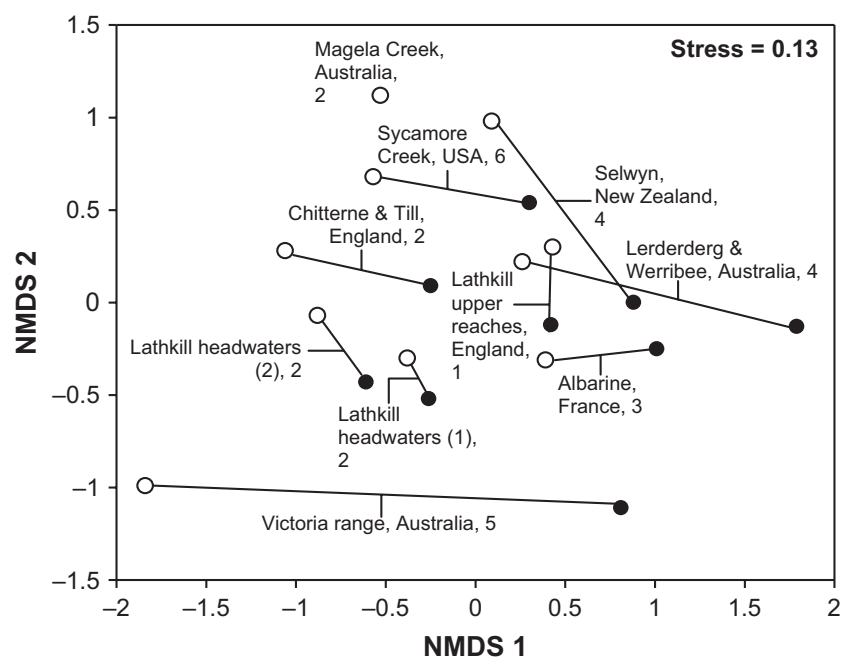

Fig. 2 Two-dimensional non-metric multidimensional scaling (NMDS) plot of macroinvertebrate assemblages in flowing river (FR) and rehydrated sediment (RS) samples across a gradient of environmental harshness (see text for determination; numbers indicate harshness ranks, where $1=$ least harsh and $6=$ most harsh). Filled symbols = FR samples; open symbols = RS samples; lines link FR and RS samples from the same system.

sharper, falling from $101 \pm 18$ individuals to $49 \pm 7$ individuals between the 0.1-7 day and 8-30 day dry period duration categories (Mann-Whitney U-test, $P=0.038$; Fig. 5b). After this initial decline, densities

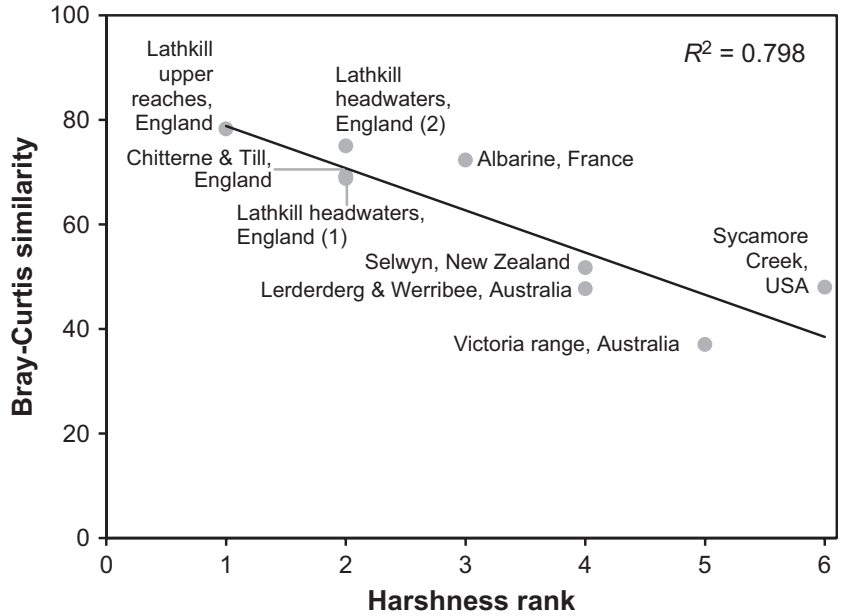

Fig. 3 Relationship between environmental harshness, and BrayCurtis similarity between flowing river and rehydrated sediment samples. See text for determination of harshness; 1 = least harsh; $6=$ most harsh.

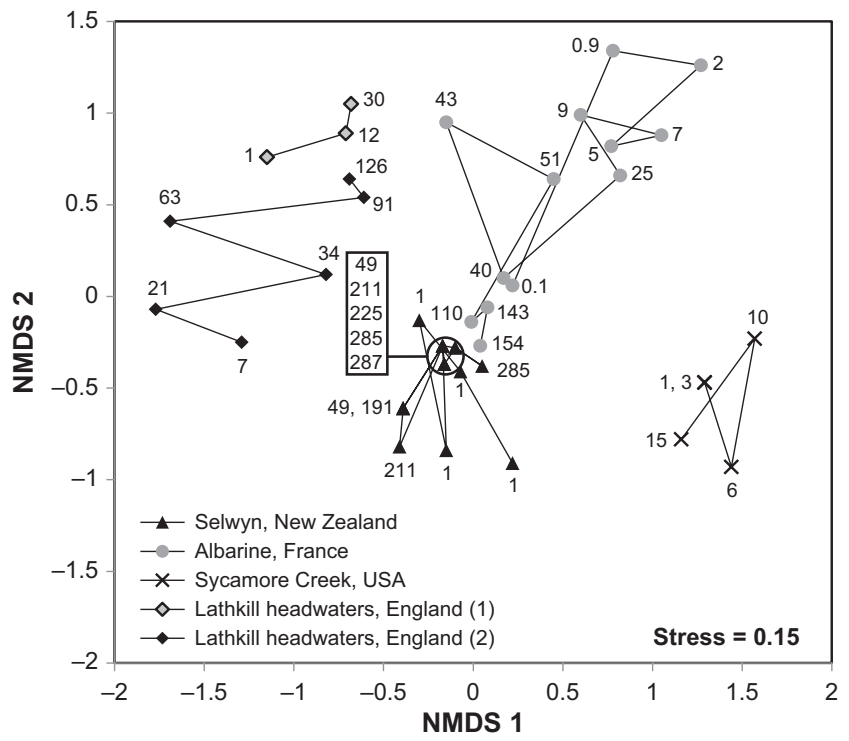

Fig. 4 Two-dimensional non-metric multidimensional scaling (NMDS) plot of macroinvertebrate assemblages in rehydrated sediment samples, along a spatial or temporal gradient of increasing dry period. Numbers indicate dry period duration (days).

remained stable for dry period durations of $<287$ days (Fig. 5b).

Relationships between dry period duration and taxon richness were system-specific and could be related to sediment moisture content (Fig. 6a). In Sycamore Creek, Stanley et al. (1994) recorded a rapid reduction in taxon richness over the 15-day study period, and although moisture data were not collected, the authors emphasised the rapidity with which sediment moisture declined in 

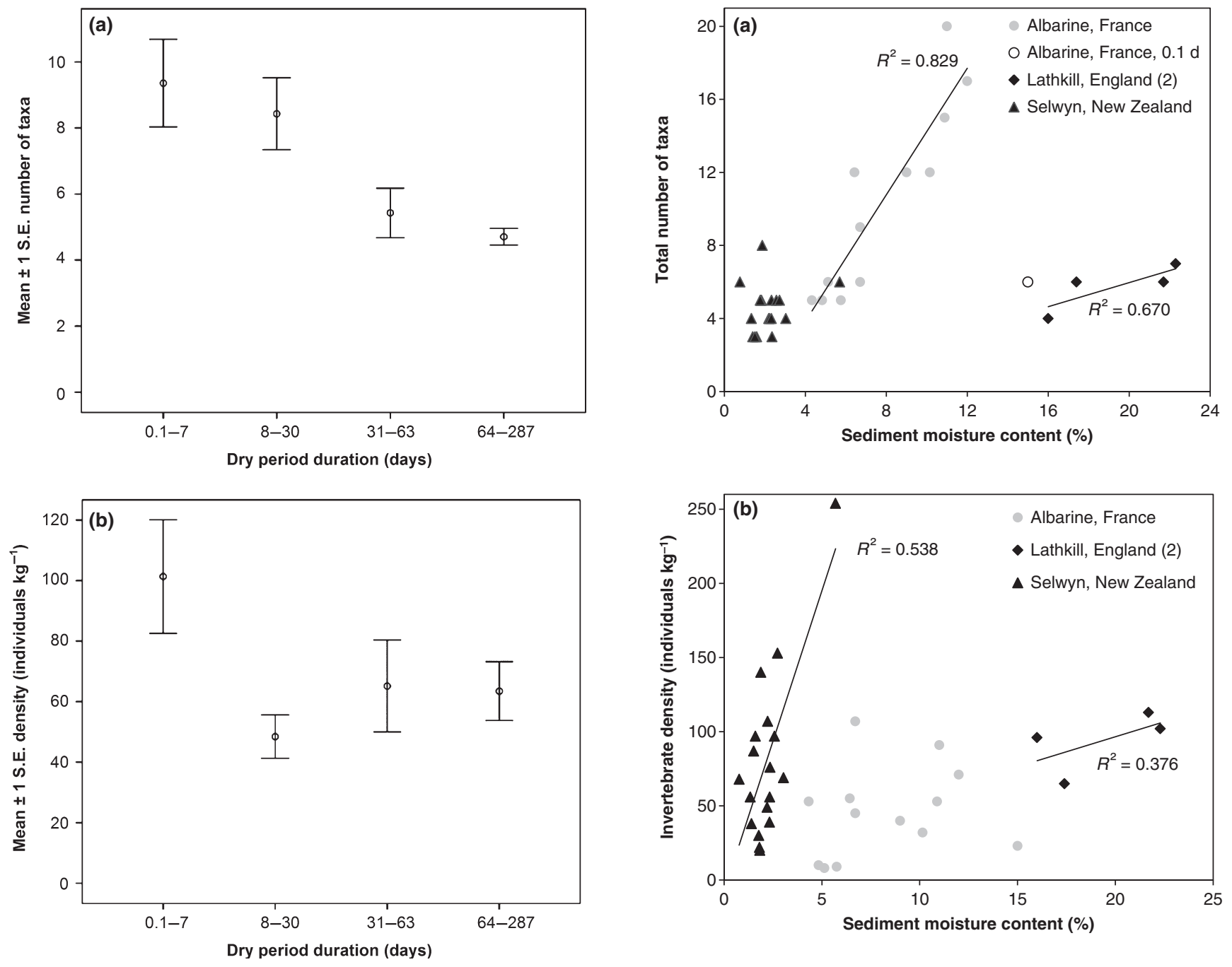

Fig. 5 Metrics for the macroinvertebrate community persisting in riverbed sediments during dry periods of different durations: mean $\pm 1 \mathrm{SE}$ (a) taxa per sample; (b) individuals $\mathrm{kg}^{-1}$ sediment. Number of samples per duration: 0.1-7 day, $n=14 ; 8-30$ day, $n=7 ; 31-63$ day, $n=7 ; 64-287$ day, $n=17$.

this arid system. A similar reduction occurred in the temperate Albarine in the first 7 days after drying (Datry et al., 2012), the rate of taxon loss then stabilising over the 142-day study period. Excepting a notable outlier for the 0.1-day dry period duration, in which few taxa were recorded despite high moisture content, a strong positive linear relationship was observed between moisture content and taxon richness in the Albarine $\left(R^{2}=0.829\right.$, $P<0.001$; Fig. 6a; Datry et al., 2012). In the temperate Lathkill headwaters, taxon richness remained stable (Stubbington et al., 2009) or increased slightly (R. Stubbington, unpubl. data a) during the dry period; stable sediment moisture content characterised this system, resulting in a positive, linear relationship with the num-

Fig. 6 Relationship between macroinvertebrate community metrics and sediment moisture content in experimentally rehydrated riverbed sediments: (a) total number of taxa; (b) densities (individuals $\mathrm{kg}^{-1}$ ). See Table 1 for site details.

ber of taxa present $\left(R^{2}=0.670\right)$ which was not significant due to the low number of samples $(P=0.181$; Fig. 6a). Similar stability in taxon richness was observed in the temperate Selwyn, but no relationship was apparent between the number of taxa and the moisture content in this study $\left(R^{2}=0.043\right.$; Fig. 6a; Larned et al., 2007).

Temporal changes in macroinvertebrate density were similar to patterns described for taxon richness, being positively related to sediment moisture in two of the three temperate systems for which data were available (Fig. 6b). However, while a strong positive linear relationship between moisture content and invertebrate densities was observed on the Selwyn $\left(R^{2}=0.538\right.$, $P=0.001)$, a moderate linear relationship was observed in the Lathkill headwaters $\left(R^{2}=0.376, P=0.387\right)$ and no relationship was apparent in the Albarine (Fig. 6b). 


\section{Seedbank importance in relation to community resilience}

In all eight studies reporting taxa in alternative recolonist sources during the dry period, at least one such habitat contained a greater proportion of FR taxa than RS samples (Table 6). Habitats supporting the greatest proportion of FR taxa were invariably perennial surface waters, namely pools (Boulton, 1989; Chester \& Robson, 2011), downstream reaches (Stubbington et al., 2009; R. Stubbington, unpubl. data a,b; P. J. Wood, unpubl. data) and upstream reaches (Larned et al., 2007; Datry et al., 2012). Reference to the raw data indicated that multiple habitats supported the same recolonists; for example, all taxa recorded in groundwater springs by Stubbington et al. (2009) also occurred in downstream perennial reaches. Some taxa were recorded exclusively in RS samples in four studies: Boulton (1989), Stubbington et al. (2009), Stubbington (R. Stubbington, unpubl. data) and Wood (P. J. Wood, unpubl. data). Boulton (1989), for example, found Scirtidae (Coleoptera), Ceratopogonidae, Dolichopodidae, Psychodidae (Diptera), Glacidobidae (Gastropoda) and Calocidae (Trichoptera) in RS and no other habitat sampled during the dry phase, while Stubbington et al. (2009) recorded Dytiscidae, Hydrophilidae (Coleoptera), Dixidae (Diptera) and Nemoura cambrica (Plecoptera, Nemouridae) only in RS.

\section{Discussion}

Previous research has indicated that macroinvertebrate community persistence in temporary rivers is achieved primarily through resilience mechanisms (Stanley et al., 1994; Fritz \& Dodds, 2004; Acuña et al., 2005; Chester \& Robson, 2011), and the capacity of dry sediments to enhance community resistance has been considered low (Boulton \& Stanley, 1995; Young, Norris \& Sheldon, 2011). Our analysis indicated that survival within dry sediments has previously been underestimated, with a diverse macroinvertebrate assemblage including up to $54 \%$ of FR taxa emerging following rehydration of sediments collected across climate zones. Macroinvertebrates survived alongside an abundant meiofauna, which was beyond the scope of our analysis; our determination of seedbank importance is therefore likely to remain an underestimate for the entire invertebrate community. The small size of RS sampling areas may also have reduced our richness estimates: riverbed sediments are heterogeneous, and consequent spatial variability in assemblage composition (Townsend \& Hildrew, 1994) may have excluded some taxa. This is demonstrated, for example, by Chester \& Robson's (2011) observation of the FR crayfish Geocharax in aestivation chambers constructed beneath cobbles in the dry thalweg, but not in RS.

\section{Seedbank importance in relation to environmental harshness}

We predicted that seedbank importance would decrease with increasing environmental harshness and that this would be observed as a reduction in similarity between FR and RS assemblages as harshness increased. The negative linear relationship observed between harshness and the proportion of FR taxa in RS samples largely supported this prediction, although the high proportion of the FR assemblage present in RS from the harshest system (Sycamore Creek, Stanley et al., 1994) was a notable outlier and reflected the presence of a high proportion of a taxon-poor FR assemblage in RS. The declining proportion of the FR assemblage in RS contributed to these assemblages becoming more distinct as harshness increased.

Moisture content is considered to be a crucial influence on seedbank viability (Stanley et al., 1994; Tronstad et al., 2005a). Moisture is influenced by climate (precipitation, temperature, humidity), shading, sediment characteristics (hydraulic conductivity, grain size distribution, organic matter content) and surface microhabitats that limit evaporation (e.g. leaf packs; Paltridge et al., 1997), as well as the dry period duration. Regression analyses confirmed the importance of moisture as a determinant of assemblage richness and density in temperate systems, but with some exceptions; these are tentatively attributed to a coarse temporal sampling resolution at short dry period durations (Larned et al., 2007) and spatial heterogeneity of invertebrate densities within dry sediments (Datry et al., 2012). Relationships with sediment moisture were stronger for taxon richness than invertebrate densities, with taxa needing only to survive at low densities to facilitate community recovery upon rewetting.

\section{Effect of sediment moisture on the seedbank assemblage}

For the seedbank to function as a resistance mechanism, inhabitants must survive an entire dry phase, which may vary from hours to months (Larned et al., 2007). However, invertebrate density and taxon richness were negatively related to sediment moisture content and consequently experienced pronounced temporal reductions in both arid and temperate systems that lacked significant dry-phase precipitation (Stanley et al., 1994; Larned 


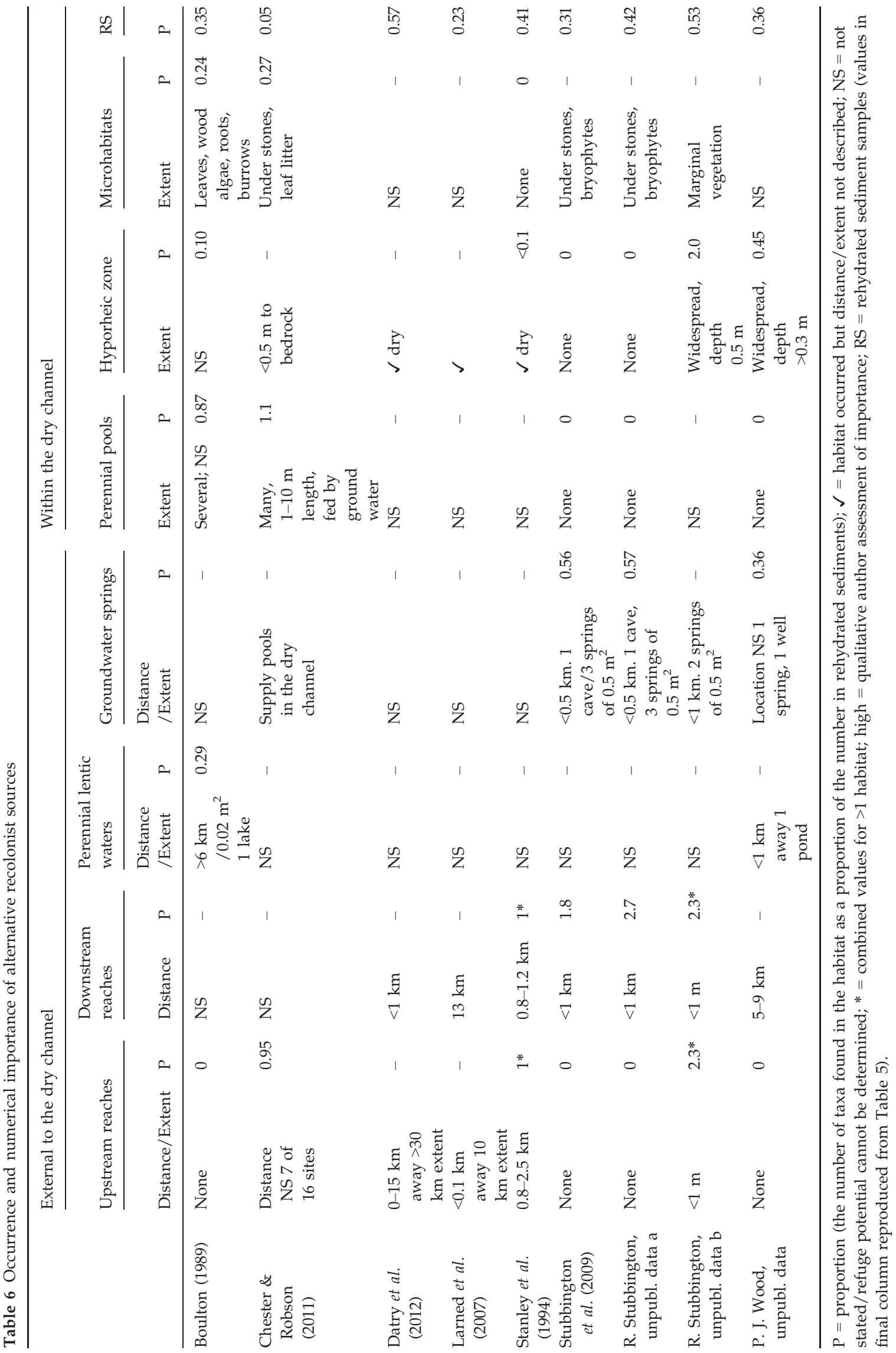


et al., 2007; Datry et al., 2012). In such systems, seedbank importance decreased with dry period duration, due to fewer taxa and individuals having the physiological traits required to tolerate complete desiccation (Robson et al., 2011; Wickson et al., 2012; Poznańska et al., 2013). However, a linear relationship between time and moisture should not be assumed, and where moisture is maintained by precipitation in conjunction with other variables (e.g. shading, organic-rich sediments), this is reflected by stable assemblage composition (R. Stubbington, unpubl. data a). Stubbington et al. (2009) even recorded a temporal increase in seedbank richness during a year of high rainfall in the temperate Lathkill headwaters, with terrestrial adult insects potentially adding taxa through oviposition (Towns, 1983).

\section{Seedbank importance within wider community persistence strategies}

Alternative sources of recolonists, particularly perennial surface waters, supported more FR taxa than RS. This finding is consistent with reports that temporary river communities recover primarily through resilience, with recolonists from perennial upstream reaches (Fritz \& Dodds, 2004; Bogan \& Lytle, 2007; Corti \& Datry, 2012), instream pools (Boulton, 1989; Chester \& Robson, 2011), connected lentic waters (Paltridge et al., 1997) and aerial recolonists (Carl, 1989; Gagneur \& Chaoui-Boudghane, 1991) contributing to recovery. Downstream perennial reaches may also be inhabited by many FR taxa (Arscott et al., 2010; R. Stubbington, unpubl. data a) and are important recolonist pools for positively rheotactic taxa (Hughes, 1970; Hultin, 1971). In addition, the hyporheic zone may support FR taxa and can therefore contribute to community resilience (Datry, Larned \& Scarsbrook, 2007; Datry, 2012; Stubbington, 2012); these saturated sediments form a temporal ecotone that may dry to be inhabited by a desiccation-tolerant seedbank. Complementing these resilience mechanisms, microhabitats promoting community resistance within a dry reach include riparian plant roots (Fritz \& Feminella, 2011) and leaf litter (Boulton, 1989; Chester \& Robson, 2011; Wickson et al., 2012). Our results, however, suggest that the seedbank is the resistance mechanism supporting the richest assemblage. Recolonist sources may show considerable redundancy (Robson et al., 2011); for example, the assemblage in upwelling springs may be a subset of that in downstream perennial reaches (Stubbington et al., 2009). Such redundancy facilitates community persistence: if the viability of one habitat is compromised, others may still function. Redundancy was, however, less pronounced for RS than other recolonist sources, with Diptera, Coleoptera, Trichoptera and Plecoptera taxa being found exclusively in RS (e.g. Boulton, 1989; Stubbington et al., 2009).

The seedbank therefore forms a single element in an armoury of community persistence mechanisms. From a landscape perspective, the spatial arrangement of temporary reaches, perennial waters and other sources from which recolonists originate (Lake, 2003) affects the extent to which different habitats function as refuges (Davey \& Kelly, 2007). The seedbank may therefore be a particularly important resistance mechanism in certain areas, including headwaters (which lack perennial upstream reaches), reaches several $\mathrm{km}$ downstream of perennial water (Paltridge et al., 1997), isolated catchments (with limited aerial recolonisation) and reaches lacking saturated hyporheic sediments (Datry, 2012). The seedbank may also have particular value for certain taxa, including those with low dispersal and recolonisation abilities (Robson et al., 2011) such as insects whose adults are weak fliers (e.g. some Ephemeroptera and Plecoptera genera; Churchel \& Batzer, 2006). These taxa must, however, have some physiological tolerance of desiccation to survive in the seedbank (Robson et al., 2011). In addition, our analysis indicated the seedbank as particularly important in certain environments, with the proportion of FR taxa supported by RS being greatest in less harsh systems, typically in temperate climates. Relatively few studies have been conducted in non-temperate climate zones, and further research is therefore required to establish whether the patterns observed in our study were typical.

\section{Recreating inundation: current practice and future challenges}

Rewetting of a dry reach represents a short phase of high biological activity following a longer period of quiescence, or a 'hot moment' (McClain et al., 2003), in which many taxa simultaneously start to develop (Larned et al., 2007). Once the fundamental criterion of free water has been met, other secondary variables influence development, including temperature (Newell \& Minshall, 1978; Zwick, 1996) and chemical signals (Jensen, Carlson \& Barnard, 1999; Evans \& Dennehy, 2005). Conditions of experimental rehydration must therefore adequately represent field conditions, but to date, studies have differed in their replication of various parameters. Firstly, no experiment has attempted to simulate flowing water, and although hydraulic cues that break dormancy are poorly understood (Brock et al., 2003), simple inundation may not trig- 
ger development in some taxa (Danks, 1987). Second, while some studies have replicated a natural light/dark cycle (e.g. Datry et al., 2012), others have covered containers to prevent loss of emerging insects (e.g. Stubbington et al., 2009), obscuring photoperiod-related cues (Chapman, 1998). Third, some studies have kept samples at ambient temperatures (e.g. Stubbington et al., 2009), while others have followed constant temperature regimes (e.g. Datry et al., 2012), suppressing thermal development triggers (Zwick, 1996). Other relevant factors include the occurrence of aquatic and riparian predators (Larned et al., 2007), and the duration of rehydration. The latter should be sufficient for macroinvertebrates to develop to an identifiable stage, which may exceed the 28 to 32 day duration typically used (Jackson \& Sweeney, 1995), particularly since physiological desiccation tolerance often involves entering a resting state (Williams, 1996) and subsequent development in response to inundation may be delayed (Wickson et al., 2012). It is noteworthy that the sole plecopteran (Brachyptera risi) recorded by Stubbington (R. Stubbington, unpubl. data a) occurred in a single RS sample rehydrated for 9 months. Future rehydration experiments should seek to manipulate biotic and abiotic parameters to promote development of seedbank inhabitants.

Current estimates of seedbank richness may be underestimates due to the spatial design of sampling strategies. Invertebrates may follow a receding waterline in preference to burrowing into sediments, and such movements may concentrate individuals into the last microhabitats to lose free water (Larimore, Childers \& Heckrotte, 1959; Tronstad, Tronstad \& Benke, 2005b; Stubbington, Wood \& Reid, 2011a; Stubbington et al., 2011b) prior to other behaviours such as vertical migration, egg deposition and entrance into a desiccation-resistant dormant state. This relocation over small spatial scales increases existing heterogeneity in invertebrate distribution. Sampling designs should therefore be informed by observation of hydrological conditions preceding the dry phase.

\section{Seedbank importance in a changing climate}

Previous conceptualisation of dry riverbeds as biologically inactive (Stanley, Fisher \& Grimm, 1997) has left dry reaches vulnerable to anthropogenic impacts (Larned et al., 2010). However, recognition that dry sediments contribute to aquatic community persistence provides impetus for their protection (Steward et al., 2012). In addition, the total biota supported by temporary rivers may be high, due to temporal transitions between wet and dry phases and use of dry sediments by terrestrial and amphibious communities (Fritz \& Feminella, 2011; Corti \& Datry, 2012; Datry et al., 2012). Communities may be interdependent due to reciprocal energy exchanges (Nakano \& Murakami, 2001; Fritz \& Feminella, 2011), with aquatic taxa providing prey for riparian predators (Paetzold, Bernet \& Tockner, 2006; Greenwood \& McIntosh, 2010) and aquatic predators exploiting inputs of terrestrial prey engulfed by advancing wetted fronts (Corti \& Datry, 2012).

With climate change scenarios predicting an increase in drought severity (Solomon et al., 2007) and therefore in the extent and duration of riverbed drying (Sponseller et al., 2010; Döll \& Schmied, 2012), ensuring the integrity of persistence mechanisms used by temporary river communities is an increasing priority. Climate change adaptation strategies need to be system specific (Aldous et al., 2011) and the importance of protecting dry sediments as a feature promoting community resistance should therefore be judged on a site-by-site basis. Where the seedbank is found to be of high value, action may be required to protect its ecological integrity. Our analysis identified strong relationships between sediment moisture and taxon richness, and rehabilitation and management strategies should therefore aim to maintain moisture content during periods of low precipitation. Such efforts could manipulate any parameter influencing moisture including, for example, sediment organic matter content or shading of the dry reach. As such, consideration of both riparian and instream habitats may help to maintain a rich seedbank that promotes community resistance to riverbed drying.

\section{Acknowledgements}

We extend our grateful thanks to Paul J. Wood and Scott T. Larned for allowing us to include their unpublished data and Emily H. Stanley and Andrew J. Boulton for supporting our work. Thanks to Alexandra Pitcher for her contribution to the study of P. J. Wood (unpubl. data). We also thank Paul, Scott, Andrew, Belinda Robson and an anonymous reviewer for insightful comments that greatly improved this manuscript. Unpublished data from RS were collected with the support of a Faculty of Social Sciences and Humanities Research Studentship from Loughborough University.

\section{References}

Acuña V., Muñoz I., Adonis G., Omella M., Sabater F. \& Sabater S. (2005) Drought and postdrought recovery cycles 
in an intermittent Mediterranean stream: structural and functional aspects. Journal of the North American Benthological Society, 24, 919-933.

Aldous A., Fitzsimons J., Richter B. \& Bach L. (2011) Droughts, floods and freshwater ecosystems: evaluating climate change impacts and developing adaptation strategies. Marine and Freshwater Research, 62, 223-231.

Arscott D.B., Larned S.T., Scarsbrook M.R. \& Lambert P. (2010) Aquatic invertebrate community structure along an intermittence gradient: Selwyn River, New Zealand. Journal of the North American Benthological Society, 29, 530-545.

Benigno G.M. \& Sommer T.R. (2008) Just add water: sources of chironomid drift in a large river floodplain. Hydrobiologia, 600, 297-305.

Bogan M.T. \& Lytle D.A. (2007) Seasonal flow variation allows 'time-sharing' by disparate aquatic insect communities in montane desert streams. Freshwater Biology, 52, 290-304.

Bogan M.T. \& Lytle D.A. (2011) Severe drought drives novel community trajectories in desert stream pools. Freshwater Biology, 56, 2070-2081.

Boulton A.J. (1989) Over-summering refuges of aquatic macroinvertebrates in two intermittent streams in central Victoria. Transactions of the Royal Society of South Australia, 113, 23-34.

Boulton A.J. \& Lake P.S. (1992) The macroinvertebrate assemblages in pools and riffles in two intermittent streams (Werribee and Lerderderg Rivers, southern central Victoria. Occasional Papers from the Museum of Victoria, 5, 55-71.

Boulton A.J. \& Lloyd L.N. (1992) Flooding frequency and invertebrate emergence from dry floodplain sediments of the River Murray, Australia. Regulated Rivers: Research $\mathcal{E}$ Management, 7, 137-151.

Boulton A.J., Peterson C.G., Grimm N.B. \& Fisher S.G. (1992) Stability of an aquatic macroinvertebrate community in a multiyear hydrologic disturbance regime. Ecology, 73, 2192-2207.

Boulton A.J. \& Stanley E.H. (1995) Hyporheic processes during flooding and drying in a Sonoran Desert stream 2. Faunal dynamics. Archiv für Hydrobiologie, 134, 27-52.

Brock M.A., Nielsen D.L., Shiel R.J., Green J.D. \& Langley J.D. (2003) Drought and aquatic community resilience: the role of eggs and seeds in sediments of temporary wetlands. Freshwater Biology, 48, 1207-1218.

Carl M. (1989) The ecology of a wadi in Iraq with particular reference to colonization strategies of aquatic macroinvertebrates. Archiv für Hydrobiologie, 116, 499-515.

Chapman R.F. (1998) The Insects: Structure and Function. Cambridge University Press, Cambridge.

Chester E.T. \& Robson B.J. (2011) Drought refuges, spatial scale and recolonisation by invertebrates in non-perennial streams. Freshwater Biology, 56, 2094-2104.

Churchel M.A. \& Batzer D.P. (2006) Recovery of aquatic macroinvertebrate communities from drought in Georgia
Piedmont headwater streams. American Midland Naturalist, 156, 259-272.

Clarke K.R. (1993) Non-parametric multivariate analyses of changes in community structure. Austral Ecology, 18, 117143.

Clarke K.R. \& Gorley R.N. (2006) PRIMER v6: User Manual/ Tutorial. PRIMER-E Ltd, Plymouth.

Corti R. \& Datry T. (2012) Invertebrate and sestonic matter in an advancing wetted front travelling down a dry riverbed (Albarine, France). Freshwater Science, 31, 11871201.

Danks H.V. (1987) Insect Dormancy: An Ecological Perspective. Biological Survey of Canada Monograph Series No. 1. National Museum of Natural Sciences, Ottawa, Canada.

Datry T. (2012) Benthic and hyporheic invertebrate assemblages along a flow intermittence gradient: effects of duration of dry events. Freshwater Biology, 57, 563-574.

Datry T., Corti R. \& Philippe M. (2012) Spatial and temporal aquatic-terrestrial transitions in the temporary Albarine River, France: responses of invertebrates to experimental rewetting. Freshwater Biology, 57, 716-727.

Datry T., Larned S.T. \& Scarsbrook M.R. (2007) Responses of hyporheic invertebrate assemblages to large-scale variation in flow permanence and surface-subsurface exchange. Freshwater Biology, 52, 1452-1462.

Davey A.J.H. \& Kelly D.J. (2007) Fish community responses to drying disturbances in an intermittent stream: a landscape perspective. Freshwater Biology, 52, 1719-1733.

Diaz A.M., Alonso M.L.S. \& Gutierrez M.R.V.-A. (2008) Biological traits of stream macroinvertebrates from a semiarid catchment: patterns along complex environmental gradients. Freshwater Biology, 53, 1-21.

Dietz-Brantley S.E., Taylor B.E., Batzer D.P. \& DeBaise A.E. (2002) Invertebrates that aestivate in dry basins of Carolina bay wetlands. Wetlands, 22, 767-775.

Döll P. \& Schmied H.M. (2012) How is the impact of climate change on river flow regimes related to the impact on mean annual runoff? A global-scale analysis. Environmental Research Letters, 7, 014037.

Evans M.E.K. \& Dennehy J.J. (2005) Germ banking: bethedging and variable release from egg and seed dormancy. The Quarterly Review of Biology, 80, 431-451.

Fenoglio S., Bo T. \& Bosi G. (2006) Deep interstitial habitat as a refuge for Agabus paludosus (Fabricus) (Coleoptera: Dytiscidae) during summer droughts. The Coleopterists Bulletin, 60, 37-41.

Fritz K.M. \& Dodds W. (2005) Harshness: characterisation of intermittent stream habitat over space and time. Marine and Freshwater Research, 56, 13-23.

Fritz K.M. \& Dodds W.K. (2004) Resistance and resilience of macroinvertebrate assemblages to drying and flood in a tallgrass prairie stream. Hydrobiologia, 527, 99-112.

Fritz K.M. \& Feminella J.W. (2011) Invertebrate colonization of leaves and roots within sediments of intermittent 
coastal plain streams across hydrologic phases. Aquatic Sciences, 73, 459-469.

Gagneur J. \& Chaoui-Boudghane C. (1991) Sur le role du milieu hyporhéique pendant $\mathrm{l}^{\prime}$ assèchement des oueds de l'Ouest Algérien. Stygologia, 6, 77-89.

Gasith A. \& Resh V.H. (1999) Streams in Mediterranean climate regions: abiotic influence and biotic responses to predictable seasonal events. Annual Review of Ecology \& Systematics, 30, 51-81.

Greenwood M.J. \& McIntosh A.R. (2010) Low river flow alters the biomass and population structure of a riparian predatory invertebrate. Freshwater Biology, 55, 2062-2076.

Hughes D.A. (1970) Some factors affecting drift and upstream movements of Gammarus pulex. Ecology, 51, 301-305.

Hultin L. (1971) Upstream movements of Gammarus pulex pulex (Amphipoda) in a South Swedish stream. Oikos, 22, 329-347.

Jackson J.K. \& Sweeney B.W. (1995) Egg and larval development times for 35 species of tropical stream insects from Costa-Rica. Journal of the North American Benthological Society, 14, 115-130.

Jensen T., Carlson D.A. \& Barnard D.R. (1999) Factor from swamp water induces hatching in egg of Anopheles diluvialis (Diptera: Culicidae) mosquitoes. Environmental Entomology, 28, 545-550.

Kenk R. (1949) The animal life of temporary and permanent ponds in Southern Michigan. Miscellaneous Publication from the Museum of Zoology at the University of Michigan, 71, 1-66.

Kundzewicz Z.W., Mata L.J., Arnell N.W., Döll P., Jimenez B., Miller K. et al. (2008) The implications of projected climate change for freshwater resources and their management. Hydrological Sciences Journal, 53, 3-10.

Lake P.S. (2003) Ecological effects of perturbation by drought in flowing waters. Freshwater Biology, 48, 1161-1172.

Larimore R.W., Childers W.F. \& Heckrotte C. (1959) Destruction and re-establishment of stream fish and invertebrates affected by drought. Transactions of the American Fisheries Society, 88, 261-285.

Larned S., Datry T., Arscott D. \& Tockner K. (2010) Emerging concepts in temporary-river ecology. Freshwater Biology, 55, 717-738.

Larned S.T., Datry T. \& Robinson C.T. (2007) Invertebrate and microbial responses to inundation in an ephemeral river reach in New Zealand: effects of preceding dry periods. Aquatic Sciences, 69, 554-567.

Lysne S. \& Koetsier P. (2006) Experimental studies on habitat preference and tolerances of three species of snails from the Snake River of southern Idaho, U.S.A. American Malacological Bulletin, 21, 77-85.

Lytle D.A. \& Poff N.L. (2004) Adaptation to natural flow regimes. Trends in Ecology \& Evolution, 19, 94-100.

McClain M., Boyer E., Dent C., Gergel S., Grimm N., Groffman P. et al. (2003) Biogeochemical hot spots and hot moments at the interface of terrestrial and aquatic ecosystems. Ecosystems, 6, 301-312.
Miller A.C., Ponder W.F. \& Clark S.A. (1999) Freshwater snails of the genera Fluvidona and Austropyrgus (Gastropoda, Hydrobiidae) from northern New South Wales and southern Queensland, Australia. Invertebrate Taxonomy, 13, 461-493.

Nakano S. \& Murakami M. (2001) Reciprocal subsidies: dynamic interdependence between terrestrial and aquatic food webs. Proceedings of the National Academy of Sciences of the United States of America, 98, 166-170.

Newell R.L. \& Minshall G.W. (1978) Effect of temperature on the hatching time of Tricorythodes minutus (Ephemeroptera: Tricorythidae). Journal of the Kansas Entomological Society, 51, 504-506.

Paetzold A., Bernet J.F. \& Tockner K. (2006) Consumer-specific responses to riverine subsidy pulses in a riparian arthropod assemblage. Freshwater Biology, 51, 1103-1115.

Paltridge R.M., Dostine P.L., Humphrey C.L. \& Boulton A.J. (1997) Macroinvertebrate recolonization after re-wetting of a tropical seasonally-flowing stream (Magela Creek, Northern Territory, Australia). Marine and Freshwater Research, 48, 633-645.

Poznańska M., Kakareko T., Krzyżyński M. \& Kobak J. (2013) Effect of substratum drying on the survival and migrations of Ponto-Caspian and native gammarids (Crustacea: Amphipoda). Hydrobiologia, 700, 47-59.

Robson B.J., Chester E.T. \& Austin C.M. (2011) Why life history information matters: drought refuges and macroinvertebrate persistence in non-perennial streams subject to a drier climate. Marine \& Freshwater Research, 62, 801-810.

Solomon S., Qin D., Manning M., Alley R.B., Berntsen T., Bindoff N.L. et al. (2007) Technical summary. In: Climate Change 2007: The Physical Science Basis. Contribution of Working Group I to the Fourth Assessment Report of the Intergovernmental Panel on Climate Change (Eds S. Solomon, D. Qin, M. Manning, Z. Chen, M. Marquis, K.B. Averyt et al.), pp. 1991. Cambridge University Press, Cambridge.

Sponseller R.A., Grimm N.B., Boulton A.J. \& Sabo J.L. (2010) Responses of macroinvertebrate communities to long-term flow variability in a Sonoran Desert stream. Global Change Biology, 16, 2891-2900.

Stanley E.H., Buschman D.L., Boulton A.J., Grimm N.B. \& Fisher S.G. (1994) Invertebrate resistance and resilience to intermittency in a desert stream. American Midland Naturalist, 131, 288-300.

Stanley E.H., Fisher S.G. \& Grimm N.B. (1997) Ecosystem expansion and contraction in streams. BioScience, 47, $427-435$.

Steward A.L., von Schiller D., Tockner K., Marshall J.C. \& Bunn S.E. (2012) When the river runs dry: human and ecological values of dry riverbeds. Frontiers in Ecology and the Environment, 10, 202-209.

Stubbington R. (2012) The hyporheic zone as an invertebrate refuge: a review of variability in space, time, taxa and behaviour. Marine and Freshwater Research, 63, 293-311. 
Stubbington R., Greenwood A.M., Wood P.J., Armitage P.D., Gunn J. \& Robertson A.L. (2009) The response of perennial and temporary headwater stream invertebrate communities to hydrological extremes. Hydrobiologia, 630, 299-312.

Stubbington R., Wood P.J. \& Reid I. (2011a) Spatial variability in the hyporheic zone refugium of temporary streams. Aquatic Sciences, 73, 499-511.

Stubbington R., Wood P.J., Reid I. \& Gunn J. (2011b) Benthic and hyporheic invertebrate community responses to seasonal flow recession in a groundwater-dominated stream. Ecohydrology, 4, 500-511.

Tooth S. \& Nansen G.C. (2011) Distinctiveness and Diversity of Arid Zone River Systems. In: Arid Zone Geomorphology: Process, Form and Change in Drylands, 3rd edn (Ed. D.S.G. Thomas), pp. 269-300. John Wiley \& Sons Ltd, Chichester.

Towns D.R. (1983) Terrestrial oviposition by two species of caddisfly in South Australia (Trichoptera: Leptoceridae). Australian Journal of Entomology, 22, 113-118.

Townsend C. \& Hildrew A. (1994) Species traits in relation to a habitat templet for river systems. Freshwater Biology, 31, 265-275.

Tronstad L.M., Tronstad B.P. \& Benke A.C. (2005a) Invertebrate seedbanks: rehydration of soil from an unregulated river floodplain in the south-eastern U.S. Freshwater Biology, 50, 646-655.

Tronstad L.M., Tronstad B.P. \& Benke A.C. (2005b) Invertebrate responses to decreasing water levels in a subtropical river floodplain wetland. Wetlands, 25, 583-593.

Velasco J. \& Millan A. (1998) Feeding habits of two large insects from a desert stream: Abedus herberti (Hemiptera: Belostomatidae) and Thermonectus marmoratus (Coleoptera: Dytiscidae). Aquatic Insects, 20, 85-96.

Vörösmarty C.J., McIntyre P.B., Gessner M.O., Dudgeon D., Prusevich A., Green P. et al. (2010) Global threats to human water security and river biodiversity. Nature, 467, 555-561.

Wickson S., Chester E.T. \& Robson B.J. (2012) Aestivation provides flexible mechanisms for survival of stream drying in a larval trichopteran (Leptoceridae). Marine and Freshwater Research, 63, 821-826.

Williams D.D. (1996) Environmental constraints in temporary fresh waters and their consequences for the insect fauna. Journal of the North American Benthological Society, 15, 634-650.

Williams D.D. (2005) Temporary forest pools: can we see the water for the trees? Wetlands Ecology and Management, 13, 213-233.
Williams D.D. (2006) The Biology of Temporary Waters. Oxford University Press, Oxford.

Young B., Norris R. \& Sheldon F. (2011) Is the hyporheic zone a refuge for macroinvertebrates in drying perennial streams? Marine and Freshwater Research, 62, 1373-1382.

Zwick P. (1996) Variable egg development of Dinocras spp. (Plecoptera, Perlidae) and the stonefly seed bank theory. Freshwater Biology, 35, 81-100.

\section{Supporting Information}

Additional Supporting Information may be found in the online version of this article:

Appendix S1. Supporting information on unpublished studies.

Figure S1. Map of the River Lathkill, indicating the location of the seven sampling site in the study of Stubbington (R. Stubbington, unpubl. data a).

Figure S2. Map of the River Lathkill, indicating the location of the sampling sites in the study of Stubbington (R. Stubbington, unpubl. data $\mathrm{b}$; originally published in Stubbington et al. (2011b) and adapted for reproduction here from the author's original figure).

Figure S3. Map of Chitterne Brook and the River Till, indicating the location of the sampling sites in the study of Wood (P. J. Wood, unpubl. data; original drawing).

Table S1. Invertebrate taxa recorded in the karstic headwaters of the River Lathkill by Stubbington (R. Stubbington, unpubl. data a).

Table S2 Invertebrate taxa recorded the upper reaches of the River Lathkill by Stubbington (R. Stubbington, unpubl. data b).

Table S3 Invertebrate taxa recorded in two chalk streams by Wood (P. J. Wood, unpubl. data).

Table S4 Moisture content (\%) recorded in sediments extracted from the karstic headwaters of the River Lathkill by Stubbington (R. Stubbington, unpubl. data a).

Table S5 Grain size distribution of sediments extracted from the karstic headwaters of the River Lathkill by Stubbington (R. Stubbington, unpubl. data a).

Table S7 Grain size distribution of sediments extracted from the upper reaches of the River Lathkill by Stubbington (R. Stubbington, unpubl. data b).

(Manuscript accepted 24 January 2013) 